\title{
Desafios tradutórios em uma proposta de tradução epistolar
} Translation challenges on an epistolary translation proposal

\section{Angelica Micoanski Thomazine}

Universidade Federal de Santa Maria - Rio Grande do Su - Brasil

\section{Claudio Luiz da Silva Oliveira}

Universidade Federal do Acre - Acre - Brasil

\begin{abstract}
Resumo: A presente pesquisa propõe soluções tradutórias comentadas para trechos de uma carta constituída de confidências e opiniões. A carta em estudo foi enviada por Edward Gorey a Peter F. Neumeyer, na qual são emitidas opiniões sobre as suas próprias obras e sobre a literatura infantil. Busca-se demonstrar como diferentes soluções tradutórias poderiam causar diferentes impressões no leitor de chegada à luz do referencial teórico sobre correspondência (ABES, 2010; BARRENECHEA, 1990; BOHRER, 2015; BOSSIS e MCPHERSON, 1986; BOVO, 2015), sobre literatura infantil (MEIRELES, 1984; HUNT, 2010; ANDRUETTO, 2012), e sobre tradução literária (RÓNAI, 2012; SCHLEIERMACHER, 2010; BERMAN, 2007; VENUTI, 1995), entre outros. Nota-se que o tradutor precisa atentar-se à pontuação, pois é através dela que se ecoa a voz do remetente e o ritmo oral da narrativa, além das escolhas semânticas, que dão à narrativa um caráter mais formal ou informal. É necessário escolher a melhor forma de deixar clara a mensagem transmitida na correspondência entre os interlocutores, podendo buscar soluções estrangeirizadoras ou domesticadoras sem se ater apenas a uma.
\end{abstract}

Palavras-chave: Tradução Literária. Tradução Epistolar. Tradução Comentada.

Abstract: This research aims to share commented translation choices for pieces of a letter full of confidences and opinions. The letter translated and used in this paper was written by Edward Gorey and sent to Peter F. Neumeyer and it is important because of the opinions about his own works and about children's literature shared in its content. We propose to show how different translation choices might bring different impressions for the reader. In view of this, a theory review about letters is based on Abes (2010), Barrenechea (1990), Bohrer (2015), Bossis e McPherson (1986) and Bovo (2015), a review about children's literature is based on Meireles (1984), Hunt (2010), Andruetto (2012) and content about literary translation is taken from authors such as Rónai (2012), Schleiermacher (2010), Berman (2007), Venuti (1995), among others. Punctuation is an aspect the translator needs to consider because it represents the sender's oral voice and rhythm. Another important element is related to semantics, which characterizes the narrative as formal or informal and requires an attentive translator, who needs to make the letter translation clear through using both domestication and foreignization strategies.

Keywords: Literary Translation. Epistolary Translation. Commented Translation. 


\section{Introdução}

Esta pesquisa atenta-se à tradução interlingual, sendo seu objeto de estudo uma carta escrita em língua inglesa enviada por Edward Gorey a Peter F. Neumeyer durante o período em que realizaram um trabalho colaborativo. $O$ texto de partida encontra-se na obra Floating Worlds: the Letters of Edward Gorey \& Peter F. Neumeyer, editada por Neumeyer, publicada em 2011 e que contém sessenta e cinco cartas. Outras foram omitidas por conterem conteúdo considerado irrelevante pelos editores, ou por abordarem questões pessoais e por isso preferiuse que permanecessem privadas.

Os autores trocaram cartas durante treze meses, prática cuja motivação principal foi o trabalho colaborativo, pois Edward Gorey (doravante EG) havia sido convidado para ilustrar um livro de Peter F. Neumeyer (doravante PN):

A maioria da minha correspondência com Edward Gorey ocorreu durante um período de treze meses, de setembro de 1968 a outubro de 1969. O grande propósito para essa troca era a colaboração em três livros infantis nos quais eu havia escrito o texto e Ted [Edward Gorey] estava criando as ilustrações. $\mathrm{Na}$ verdade, nesse período curto as cartas iam para lá e para cá numa velocidade rápida, e seus tópicos variavam muito além dos nossos três livros. As cartas davam oportunidades para Ted articular suas visões sobre autores e artistas. Elas davam uma ideia sobre o que Ted pensava que estava fazendo conforme ele criava seu próprio trabalho. $\mathrm{E}$ elas relatam o rápido crescimento de uma amizade profunda e mútua. Pouco mais de um ano depois, a correspondência diminuiu tão abruptamente quanto começou (NEUMEYER, 2011, p. 08).

Nos paratextos da obra, PN agradece ao auxílio de Connie Vinita Dowell, amiga próxima de EG, e à Vanderbilt University pela organização de uma exibição sobre EG na Universidade Estadual de San Diego, a qual oportunizou que PN conhecesse Andreas Brown. Na ocasião, quando Brown ouviu PN ler trechos de cartas escritas por Gorey, encorajou-o a publicá-las e contou que havia guardado algumas que $E G$ recebera de PN. Outros agradecimentos são direcionados à Katie Burke, que colaborou na edição do livro e à filha do editor Harry Stanton, que autorizou que as cartas de seu pai também fossem reproduzidas. Harry Staton foi um editor que trabalhou com ambos os autores, mediou algumas de suas publicações e apresentou um ao outro, conforme pode ser observado através da leitura de outras cartas e de uma entrevista concedida por Neumeyer à Susan Resnik, em 2010.

A carta selecionada para este estudo foi enviada por EG no dia 4 de novembro de 1968 e está subdividida em quatro partes, cada qual com um assunto diferente. Por ora, interessa-nos a primeira parte da carta, selecionada por causa do tema tratado em seu conteúdo, a literatura infantil. Na primeira parte da carta é possível descobrir opiniões do remetente sobre a catalogação da literatura infantil e a forma como suas obras foram avaliadas pelos editores. A motivação para esse assunto destacar-se é devido à dificuldade que EG teve para publicar suas obras como literatura infantil, provavelmente devido à censura, com adultos que controlam os temas que podem ou não serem tratados nas obras literárias ou que determinam se uma criança está apta ou não para ler determinado livro (HUNT, 2010).

A proposta de tradução de trechos dessa carta é uma forma de revelar como EG reconhece sua própria obra e a censura na literatura infantil, tecendo comentários sobre as escolhas realizadas. O gênero carta contém particularidades que precisam ser observadas antes de se propor uma tradução. Sabese que a troca de correspondências é uma atividade que provém desde a antiguidade com diferentes propósitos, por isso propõe-se uma síntese referente ao gênero a partir de teóricos como Abes (2010), Barrenechea (1990), Bohrer (2015), Bossis e McPherson (1986), e Bovo (2015). Na carta em estudo, notam-se marcas de oralidade, referências literárias, opiniões, expressões coloquiais e elementos que nos convencem ser possível traduzi-la como sendo um texto literário, por isso buscamos referencial teórico de tradução em Rónai (2012), Schleiermacher (2010), Berman (2007) e Venuti (1995), trazendo à tona a discussão sobre estrangeirização e domesticação. Devido ao tema que motivou a seleção do texto, propõe-se retomar brevemente uma recapitulação sobre os enfrentamentos da literatura infantil 
baseando-se em Meireles (1984), Hunt (2010) e Andruetto (2012).

\section{Carta}

Popular desde a antiguidade, as cartas serviram de auxílio para que temas políticos e sociais circulassem entre diferentes pessoas e contextos, muitas vezes como uma forma de repassar uma notícia ou uma informação, outras vezes para impor regras ou orientações, ou, ainda, epístolas que transmitiam pregações aos religiosos, como as do apóstolo Paulo, que foram incluídas na Bíblia. Segundo Barrenechea (1990, p. 51), "[...] a epístola tem a vantagem de ser um produto universal que se manifesta em todas as culturas que possuem sistemas de escrita"iii. Para a autora, esse gênero exerce uma função comunicativa, mas pode também ser utilizada com outros propósitos. Além disso, através do gênero epistolar é possível perceber diferentes reações do remetente, como detalhes que nos permitem reconhecer seu caráter, seu estilo, projetos pelos quais se interessa, a imagem que tem de si mesmo e que intenta transmitir, suas opiniões sobre determinados temas ou fatos e seu humor. No caso de remetentes que são escritores, a carta nos possibilita, ainda, descobrir preocupações do remetente acerca da difusão de sua obra.

Possivelmente as cartas tenham surgido no mesmo período em que o alfabeto foi inventado, assim como a prática da escrita nas civilizações mais antigas das quais temos conhecimento (MARTíN BAÑOS, 2005; BOVO, 2015). Constata-se, por meio das referências adotadas, que as missivas eram inicialmente usadas com o propósito comercial, facilitando as transações. No entanto, com o passar do tempo, se fortalece com o objetivo de promover a interação entre pessoas ausentes no ato discursivo. Por essa razão, este gênero exige constante troca, já que, ao mesmo tempo que recebe a carta, o receptor tem a obrigação de contestá-la, tornando-se o emissor da vez. Além disso, segundo Vasconcellos (2012), apesar de não ter uma intencionalidade artística, a carta pode ser considerada um gênero literário.

Bossis e McPherson (1986, p. 63) assinalam que o gênero epistolar pode ser definido como "uma mensagem escrita por um indivíduo para outro indivíduo que está distante". Essa escrita - uma substituta do discurso direto, o qual a distância o faz impossível - tem seu valor diretamente ligado à vida diária [...]"iii. Podemos afirmar, portanto, que a troca de correspondências é, explicitamente, um diálogo entre ausentes.

"Outro aspecto bem interessante das cartas [...] é que muitas vezes elas trazem relatos de criação de uma determinada obra, desde o projeto até as etapas de elaboração, ajudando a compreender melhor a obra e a vida literária" (BOHRER, 2015, p. 71). A obra em estudo é um bom exemplo disso, afinal, o assunto principal, que deu início à troca de cartas, era 0 trabalho colaborativo que os dois autores estavam realizando. Nas primeiras cartas Neumeyer tenta explicar como ele imagina uma das ilustrações que Gorey estava desenvolvendo. Em seguida Gorey produz a ilustração e a envia à Neumeyer, para que seja avaliada. $O$ autor tece seus comentários, sugere alterações e ideias através de outra carta, dando sequência a um diálogo que continuaria até que o trabalho em andamento satisfizesse a ambos. Vasconcellos (2012, p. 62) vai um pouco além e ressalta que "as cartas são hodiernamente consideradas como parte integrante da obra de um autor, pois é comum encontrarmos a correspondência publicada junto à obra".

Além de relatos de criação, as cartas nos permitem identificar informações pessoais, detalhes biográficos que podem nos ajudar a compreender características bibliográficas. As opiniões expressas podem se alterar no decorrer das cartas, ou tornaremse contraditórias, isso se dá porque "a carta possibilita o autor expressar sentimentos pessoais à medida que os fatos ocorrem, como se fossem esses sentimentos reflexões instantâneas; daí a possibilidade de estados contraditórios e conflituosos" (BUONAFINA, 2006, p. 35).

No final da carta enviada por EG no dia 30 de outubro de 1968, por exemplo, ele questiona como Neumeyer se sentiria se tivesse que publicar seus livros para adultos ao invés de crianças, e antecipa que talvez o destinatário tenha o mesmo problema que ele 
mesmo teve quando publicou seus livros. Na carta sequencial, de 4 de novembro de 1968, que é nosso objeto de estudo, percebemos que o autor tenta explicar o porquê de sua indagação. Possivelmente essa explicação se fez necessária para que se evitasse um mal-entendido, ou para esclarecer a posição do autor sobre aquele assunto, demonstrando também certa preocupação com a difusão da obra, o que vai ao encontro das afirmações de Barrenechea (1990).

O que se pode notar no decorrer das correspondências é que embora as cartas tivessem um objetivo mais formal, como um meio de promover o diálogo sobre o trabalho que estavam realizando, aos poucos essa formalidade é substituída por um discurso muito mais amigável e informal. As correspondências aproximam o diálogo entre os artistas, assim como também permitem que o leitor se aproxime da vida cotidiana deles. Vasconcellos (2012) nos aduz a essa reflexão quanto retrata 0 caráter informal das correspondências, fato que permite o missivista "se abrir" para o seu interlocutor, garantindo-Ihe assim a visualização da sua intimidade.

\subsection{Destinatário e remetente}

O remetente da carta em estudo é Edward Gorey (1925-2000), escritor e ilustrador pós-moderno norte-americano. Escreveu e publicou mais de cinquenta obras em prosa e em poesia, estudou Literatura Francesa em Harvard, mas durante sua vida trabalhou também em outros projetos: desenhou o cenário e as roupas dos atores que interpretaram Drácula, na Broadway, dirigiu peças teatrais e teatros de fantoches e ilustrou edições de obras de outros autores, como T. S. Eliot, Edward Lear e Peter F. Neumeyer.

O destinatário é o escritor Peter F. Neumeyer, que nasceu em 1929, em Munique, na Alemanha, mudou-se para os Estados Unidos em 1936, estudou na Universidade de Berkeley, foi professor de Literatura em Harvard e na Universidade Estadual de San Diego (San Diego State University), onde institucionalizou o Departamento de Literatura Infantil, escreveu artigos sobre literatura, poesias e livros infantis.

Após serem apresentados pelo editor Harry Staton, a troca de cartas foi o meio pelo qual não apenas desenvolveram um trabalho colaborativo, mas também uma amizade. As cartas incluídas na obra The Floating World nos permitem descobrir o que os autores têm em comum, seus interesses, suas leituras, seus posicionamentos diante de outras obras e autores, de obras de arte e da literatura. O trabalho cooperativo principal era a ilustração que EG estava realizando para a obra de $\mathrm{PN}$, mas a troca de sugestões e comentários sobre os livros deles era mútua.

\subsection{0 assunto}

Edward Gorey inicia a carta descrevendo-a como fragmentada, sendo cada parcela referente a um assunto distinto. A primeira parte introduz uma possível dificuldade de PN para a publicação de um livro e apresenta um relato de experiência do remetente sobre a dificuldade que ele próprio teve com as editoras para publicar seus livros como infantis. $O$ remetente indica contrariedade em relação à avaliação editorial de sua obra ao mesmo tempo em que demonstra uma expectativa de ser lido por crianças apesar das escolhas previamente realizadas por editores. O autor relata que isso ocorreu com suas obras, as quais foram compradas por adultos, para serem lidas pelos compradores, mas no fim foram descobertas pelas crianças próximas ao comprador. A partir disso, o autor emite sua opinião sobre uma má compreensão dos editores sobre sua obra e sobre a literatura infantil, acreditando que as crianças leem o que querem, independentemente da escolha prérealizada para elas ou das que são disponibilizadas em uma catalogação editorial. Em seguida, EG discorre sobre os livros recomendados na seção de literatura infantil do jornal Times, na época, para finalizar comentando sobre a quantidade de parênteses que utilizou no último parágrafo. É dessa primeira parte que foram retirados os trechos que foram traduzidos por nós, mas acreditamos que resumir os outros assuntos 
abordados nessa carta facilita a compreensão geral do texto.

$\mathrm{Na}$ segunda parte, EG muda o foco da conversa e passa a comentar sobre um livro que leu recentemente, recomenda títulos de obras infantis de diferentes autores questionando se Zack, o filho de PN, gostaria de lê-los. Na terceira parte da carta, pede um favor ao destinatário, solicita que verifique a disponibilidade de uma obra na biblioteca de Harvard, agradece o envio de um artigo escrito por PN e comenta sobre um dos trabalhos em andamento. Esse fragmento é subdivido, o que pode ser notado por meio do horário que o remetente inclui na carta, demonstrando que o último parágrafo e o restante da carta foram escritos após um intervalo de tempo. Isso é reforçado porque EG narra ter concluído um trabalho que havia mencionado em um trecho anterior. Por fim, encerra a terceira parte opinando sobre o trabalho que havia acabado de concluir.

$\mathrm{Na}$ última parte da carta, o remetente agradece ao PN pelo pacote enviado e comenta sobre um autor, cuja obra provavelmente se encontrava nesse envio. Em seguida sugere uma data para encontrarem-se, algo que aparentemente já estava sendo combinado em outras cartas, pede ao destinatário que agradeça a outras pessoas pelo que enviaram no pacote (à Helen, esposa de PN, por uma carta, e aos filhos de PN pelos desenhos) e encerra questionando sobre um dos títulos de PN.

Nota-se que o convívio entre remetente e destinatário deixou EG à vontade para emitir suas opiniões sobre literatura infantil e sobre os editores. $O$ remetente critica a "etiquetação" nas obras infantis, o que ocorre quase como uma imposição editorial sobre o que pode ou deve ser lido pelas crianças. Segundo Andruetto (2012, p. 191), "[...] a literatura põe o leitor num lugar incômodo porque desnaturaliza o que a sociedade naturalizou, e é precisamente isso o que o pensamento globalizado pretende apagar para impor normas e formas comuns".

Por mostrar-se incômodo com a etiquetação, EG parece ir ao encontro de Azevedo (2003), quando este defende que antes mesmo de se falar em literatura infantil ou juvenil, falamos de literatura. Com isso, falamos também de estética, de discurso poético, de subjetividade, de imaginário, de especulações, de metáforas, de paradoxos, de ambiguidades, de criatividade, de transgressão linguística, de fantasia, e que temas como os conflitos entre gerações ou éticos, a passagem do tempo, as transgressões, a confusão entre realidade e fantasia, ou entre dor e prazer, a morte ou a utopia não deveriam ser vedadas das obras infantis (Azevedo, 2003).

Com diferentes avaliadores sobre a literatura infantil (escritores, editores, professores, pais etc.), ao leitor final resta um produto refinado, "despoluído" daquilo que poderia interferir na construção de um ser idealizado. A abundância de obras com qualidade duvidosa e linguagem medíocre resulta disso e a lista de sugestões de livros infantis que EG relata ter observado no jornal Times é exemplo dessa afirmação. Conforme o destinatário, nem cinco livros daquela lista valeriam a pena ser vistos.

Por outro lado, EG é amparado por Cecília Meireles (1984, p. 35) quando demonstra acreditar que as crianças em algum momento irão encontrar o que foi escrito para elas:

Os livros que hoje constituem a "biblioteca clássica" das crianças foram selecionados por elas. Muitos não traziam, inicialmente, esse destino, outros, que o traziam, inicialmente, esse destino; outros, que o traziam, foram postos de lado, esquecidos.

\section{Tradução comentada de fragmentos da carta}

É importante ressaltar que aqui nos referimos à carta conforme está editada e impressa na obra Floating Worlds the Letters of Edward Gorey \& Peter F. Neumeyer. Por isso, não iremos analisar o design dela, como a fonte utilizada ou a disposição na página. Segundo as notas editoriais da obra, as cartas originais haviam sido escritas com a utilização de máquinas de escrever, então sabe-se que o efeito visual da carta da maneira como está na obra não é o mesmo daquela originalmente enviada a Neumeyer. Apesar disso, a editora pontua que fez pouquíssimas modificações, como incluir vírgulas ou corrigir erros de grafia em casos excepcionais, mas sem alterar detalhes que 
fizessem sentido no contexto das cartas. Além disso, alguns trechos das cartas foram cortados, o que é representado através de elipses dentro de colchetes ou marcados com três asteriscos no caso de parágrafos. As elipses que não apresentam colchetes são dos próprios autores. Os sublinhados para ênfase foram mantidos na edição em estudo e os títulos de livros, peças teatrais etc. que eram originalmente escritos com pelo menos a inicial em letras maiúsculas, foram colocados em itálico ou em aspas na edição em uso. Nos casos em que não são títulos, o itálico representa anotações manuscritas feitas pelos autores na carta original. Posteriormente, destacamos alguns elementos gráficos presentes na carta, como a forma que o autor utiliza para escrever a data, destaques no texto feitos através de sublinhados, itálicos e pontuação. Em seguida, vamos tratar do conteúdo semântico da carta, ponderando sobre as possibilidades tradutórias dos trechos selecionados.

Em geral, temos dois caminhos principais, os quais já foram definidos por Schleiermacher (2010, p. 57): "Ou bem o tradutor deixa o escritor o mais tranquilo possível e faz com que o leitor vá a seu encontro, ou bem deixa o mais tranquilo possível o leitor e faz com que o escritor vá a seu encontro" e resgatados por diversos teóricos, como Venuti (1995), ao apresentar os termos estrangeirização e domesticação, ou Paulo Rónai (2012, p. 20):

Conduzir uma obra estrangeira para outro ambiente linguístico significa querer adaptá-la ao máximo aos costumes do novo meio, retirar-lhe as características exóticas, fazer esquecer que reflete uma realidade longínqua, essencialmente diversa. Conduzir o leitor para o país da obra que lê significa, ao contrário, manter cuidadosamente 0 que essa tem de estranho, de genuíno, e acentuar a cada instante a sua origem alienígena.

Ao ponderar sobre as possíveis soluções, transitamos entre esses dois caminhos. Sabe-se que de maneira geral, um irá permitir que o leitor reconheça o texto como estrangeiro enquanto o outro permite que o leitor não se aperceba que está lendo uma tradução, mas sim a obra original. Isso reflete a dicotomia que os tradutores se deparam todos os dias, entre realizar uma tradução "etnocêntrica" ou da "letra" conforme descrita por Berman (2013) ou de acordo com a nomenclatura e conceitos propostos por Venuti (1995) uma tradução "domesticadora" versus "estrangeirizadora".

Convém destacar que na tradução dos trechos da carta em análise refletimos sobre a possibilidade de qual tradução fazer: uma que se aproximasse mais da cultura do texto de chegada, doravante o texto traduzido, ou manter as marcas que gerasse uma estranheza para o leitor. Berman defende a manutenção das marcas do estrangeiro no texto de chegada, o que chama de "tradução ética". Para ele, o objetivo ético do traduzir, por se propor acolher o estrangeiro na sua corporeidade carnal, só pode estar ligado à letra da obra" (BERMAN, 2013, p. 70).

Neste mesmo sentido, Venuti (1995) ressalta que "a tradução estrangeirizante busca conter a violência etnocêntrica”. Para ele, "a tradução estrangeirizante em inglês pode ser uma forma de resistência contra o etnocentrismo e o racismo, contra o narcisismo e o imperialismo culturais em favor de relações geopolíticas democráticas" (p. 20). Sendo assim, o que Venuti ressalta é que a tradição de valorização da tradução fluente é excessivamente domesticadora, ou seja, há que se observar qual o melhor caminho a ser tomado, preferindo-se a estrangeirização e levando-se em consideração as particularidades tradutórias, afirmação anuída por Francisco (2014, p. 94) quando ressalta que "na infinidade de decisões que um tradutor toma na tradução de um texto, e considerando toda a complexidade envolvida em cada situação tradutória, seria impossível ser apenas estrangeirizante ou apenas domesticador".

Nossa proposta é, então, refletir sobre esses caminhos e seus possíveis efeitos para o leitor brasileiro da tradução dos trechos destacados, expondo qual escolha seria eleita por nós na tradução da carta.

\subsection{Elementos gráficos como representativos da oralidade}


O primeiro item apresentado na carta é a data em que foi enviada: 4.xi.68. Curiosamente, o mês de novembro é representado pelo número romano "xi", algo que costumava ser comum em cartas manuscritas e que colabora para destacar a ordem das informações: dia.mês.ano, em vez de mês.dia.ano, como é recorrente na língua inglesa. Ao traduzir tal informação, seria possível mantê-la da mesma forma como foi escrita no texto de partida, pois o leitor de chegada certamente compreenderia, já que os números romanos, apesar de não serem muito utilizados, são reconhecíveis para o leitor brasileiro. Deixar a data tal qual está no texto de partida, faria com que o leitor fizesse uma breve pausa para interpretar os números romanos e transformá-los mentalmente em números arábicos. O efeito de incluir números romanos para destacar a ordenação dia/mês/ano provavelmente passaria despercebido pelo leitor de chegada, que já adota essa ordem. Outra opção tradutória seria domesticar a data, utilizando números arábicos em vez de romanos: 4.11 .68 ou 4/11/68. A nosso ver, isso seria uma perda estilística do remetente, que ilustra um caráter formal e literário já no texto de partida.

Quanto à forma escolhida para destacar palavras e termos, deixamos de lado os títulos, que estão em itálico e destacamos as pontuações e sublinhados, que recriam marcas da oralidade através do texto escrito: palavras sublinhadas, que ilustram ênfase; aspas, que identificam citações; pontos de interrogação, que em determinados momentos são questionamentos que o autor faz a si mesmo, como perguntas retóricas, mas em outros momentos são perguntas que dialogam com 0 destinatário e parênteses, que parecem ilustrar os pensamentos que surgem na mente do remetente conforme ele escreve a carta.

A única palavra sublinhada na primeira parte da carta é o verbo auxiliar has presente no primeiro parágrafo, no qual EG descreve como será a carta e introduz o primeiro assunto utilizando uma citação de Arthur Hugh Clough: Say not the struggle naught availeth. Essa citação é utilizada para descrever seus sentimentos em relação às ilustrações para um livro de óperas que o autor estava finalizando. Logo após citar Clough, o autor destaca: [...] but it has been a struggle. O fato de ter sublinhado o verbo auxiliar ao invés de qualquer outro termo enfatiza o período ao qual o autor se refere, como se quisesse demonstrar que não era uma dificuldade instantânea, ou que estivesse ocorrendo apenas enquanto escrevia a carta, ou por poucos dias. A utilização do Present Perfect com ênfase no verbo auxiliar demonstra que a dificuldade já havia iniciado anteriormente e perdurava.

Ao traduzir esse trecho, essa ênfase não pode ser ignorada, mas o desafio seria escolher qual termo sublinhar. Uma possibilidade é: "mas está sendo uma luta". A utilização do gerúndio enfatiza o tempo presente, não recuperando a mesma imagem do texto de partida. Outra opção seria "mas tem sido uma luta", utilizando o pretérito perfeito composto, que ilustra tratar-se de uma ação que teve seu início anteriormente e permanece acontecendo pelo menos até a escrita da carta. A primeira solução soa mais natural para o leitor brasileiro, por tratar-se de um tempo verbal utilizando mais recorrentemente. Já a segunda resgata o tempo verbal, mas é mais formal e, com isso, menos utilizada. Nesse caso, optaríamos pela primeira possibilidade, pois a ênfase representa uma entonação oral, optar por um tempo verbal mais utilizado pelo falante brasileiro fluiria melhor a leitura da carta.

Sendo a carta um gênero que pode ser lido em voz alta, de forma a tentar recriar o tom de voz utilizado pelo autor, as pontuações são capazes de representar graficamente as pausas a serem realizadas. A primeira parte da carta é composta de dois parágrafos. $O$ primeiro é curto e introduz o assunto da carta e o sentimento de EG em relação ao trabalho que estava desenvolvendo, enquanto o segundo é um parágrafo longo, composto de 10 períodos e com 25 linhas, então a pontuação é que vai guiar o ritmo do texto. No início desse parágrafo, EG resgata um assunto que estava sendo dialogado e esclarece o que quis dizer, nos dando a impressão de temer ter sido mal compreendido. O tema aqui referese à dificuldade que EG enfrentou ao publicar suas 
obras como infantis e suas primeiras opiniões sobre o assunto

O primeiro ponto de interrogação ocorre em um questionamento entre parênteses: (how's that for prepared backsliding?). No período anterior, o autor havia dito que deveria estar disposto a lutar, pelo menos por um momento, para que seus livros fossem publicados como infantis, então os parênteses ilustram uma digressão reflexiva, na qual EG avalia sua própria afirmação sem esperar uma resposta do destinatário. Em cartas, as digressões não podem ser vistas como rupturas no processo discursivo no momento da interação (ANDRADE, 2002; TESCH, 2016), mais ainda quando estamos nos referindo ao discurso entre ausentes, como é o caso.

Logo em seguida, volta sua atenção à obra de PN, considerando que o destinatário não teria os mesmos problemas que EG teve, mas pontua um elemento na obra do destinatário que poderia incomodar os editores. O autor insere uma nova citação, em aspas, seguida de um comentário entre parênteses: 'images of the evening' (a phrase I came across in Dorothy Wordsworth last night) para mencionar o que ele acha que incomoda os editores em obras infantis. Diferentemente da citação incluída no primeiro parágrafo da carta, nesta temos a identificação da autora, informação extra que contextualiza a origem daquele pensamento - a frase citada se encaixa na descrição do problema que EG quis salientar e coincidentemente foi identificada na leitura que o autor fez na noite anterior à escrita da carta. Os parênteses ilustram que aquele comentário é um complemento à informação, com o propósito de assegurar a compreensão do destinatário.

Ao final da carta, temos o seguinte trecho, no qual também pode ser visualizada a utilização dos parênteses:

(I went through the Children's book section of the Times yesterday, growing more and more annoyed and gloomy; I could find maybe five books, and those by authors I was already familiar with that sounded even worth looking into, and as usual most of the artists on the ten best list are the sort that drive me up the wall. (Incidentally, should you ever wish to add a note of extreme acerbity - a word I have never to my knowledge used before - to a conversation of ours just say watermelon pickle; I think we could have a real knockdowndragout on the subject.)) What else are these $(())$ ? (GOREY, 2011, p. 89).

Aqui observamos que conforme os pensamentos fluem, eles são registrados na carta entre parênteses e no final o remetente demonstra perceber a frequência do uso.

Ao traduzir um texto, não se pode ignorar a pontuação, pois o ritmo do discurso, as entonações e possíveis intenções são representadas através dela. Sendo assim, não alterar a pontuação ao traduzir é uma forma de não interferir no ritmo do texto (GALINDO, 2016). Dessa forma, acreditamos ser necessário preservar tanto os parênteses, que trazem principalmente explicações extras, como as perguntas, que transmitem a ideia de diálogo. Outros sinais de pontuação, como vírgulas, ponto final ou ponto-evírgula colaboram para o ritmo da carta, ilustram um discurso mais acelerado quando há ausência de pontos ou períodos muito longos, ou mais pausado, caso se tenha períodos curtos ou muitas pausas, mas demandam um estudo mais detalhado, por isso não foram explorados aqui.

\subsection{Desafios tradutórios semânticos}

Os trechos aqui destacados, traduzidos e comentados foram selecionados por considerarmos desafiadores. A maioria deles foram parafraseados nas seções anteriores e serão agora apresentados em pequenos quadros que incluem o texto de partida e a nossa proposta de tradução (texto de chegada), seguido de comentários sobre as escolhas realizadas.

Quadro 1 - Trecho retirado da carta em que consta desafios tradutórios semânticos e poético e respectiva tradução

\begin{tabular}{|l|l|}
\hline \multicolumn{1}{|c|}{ TEXTO DE PARTIDA } & \multicolumn{1}{c|}{ TEXTO DE CHEGADA } \\
\hline $\begin{array}{l}\text { This will be one of those } \\
\text { installment-type things, } \\
\text { and very scrappy I } \\
\text { expect. 'Say not the } \\
\text { struggle naught }\end{array}$ & $\begin{array}{l}\text { Esta será uma daquelas coisas } \\
\text { estilo fascículo, e muito } \\
\text { fragmentadas, eu adianto. } \\
\text { 'Não diga a luta nada serve', } \\
\text { seja quem for, pois estou na }\end{array}$ \\
\hline
\end{tabular}


availeth', whoever did, for

I am on the next to last drawing for the opera book, but it has been a struggle, and last week was so to speak kneedeep in mud.

Fonte: GOREY (2011)

O trecho no Quadro 1 é o primeiro parágrafo da carta, do qual gostaríamos de destacar as frases: installment-type things, and very scrappy, a citação 'Say not the struggle naught availeth' e a expressão 'knee-deep in mud'. Em installment-type things temos uma ambiguidade, pois installment pode se referir a fascículo (um folheto ou obra que é publicada por partes), ou em prestações. A nosso ver, ambas as possibilidades resgatam a ideia principal, que é descrever a organização da carta por partes, mas optamos por "estilo fascículo" para poder recuperar também a referência literária que acreditamos que 0 autor gostaria de transmitir, pois EG sempre menciona autores, obras, exemplos e citações, indicando um vasto conhecimento literário. Em very scrappy, o autor demonstra que além de a carta estar separada por partes, elas estão incompletas, são ideias inconclusas e que estão fragmentadas, sendo esta a nossa escolha tradutória.

A citação 'Say not the struggle naught availeth' poderia não ter sido traduzida, por se tratar de um verso de um terceiro autor, retirado da poesia de Arthur Hugh Clough, poeta britânico, da Era Vitoriana. A citação ilustra como EG se sente em relação a um trabalho em andamento. Não traduzir o verso seria uma forma de permitir que o leitor busque pela fonte da citação para em seguida compreender por que EG a incluiu na carta. Ao realizar uma breve pesquisa, o leitor logo descobriria o autor da citação e o contexto em que o poema de Clough foi escrito. Nota-se que na carta não há a identificação do autor da citação, pressupõe-se que PN identificaria a fonte da citação com facilidade, então seria aceitável não traduzir a citação e permitir que o leitor do texto de chegada faça essa busca. Por outro lado, não traduzir a citação poderia acarretar perda semântica para o leitor de chegada caso não reconhecesse a citação, sua autoria ou a ideia geral intrínseca. Com isso, incluir uma nota de rodapé explicando essas informações seria útil para o leitor.

Uma segunda possibilidade seria traduzir 0 verso, o que a nosso ver exigiria que o tradutor se atentasse ao ritmo poético. Essa escolha não interromperia a compreensão do leitor, que notaria tratar-se de um verso e compreenderia o sentido geral da citação no contexto incluído por EG. Acreditamos que também caberia incluir uma nota de rodapé que incluísse o verso na língua inglesa e para identificar sua autoria. Em ambos os casos defendemos que uma nota de rodapé ajudaria a situar o leitor que talvez não reconheça o verso, cientes de que isso quebraria o ritmo da leitura da carta (RÓNAI, 2012).

Quanto à expressão knee-deep in mud, nos faz imaginar uma pessoa literalmente presa na lama, sem conseguir sair, andar ou movimentar-se. Traduzir por "afundado na lama" manteria a imagem criada pelo autor, mas não teria o mesmo sentido para o leitor de chegada, por isso optamos por "atolado", que recupera a ideia geral, recupera parcialmente a imagem criada pela expressão e é uma expressão coloquial que demonstra que a pessoa está cheia de trabalho.

No Quadro 2, apresentamos dois excertos nos quais $E G$ se posiciona com sinceridade sobre a literatura infantil e sobre os editores.

Quadro 2 - Trecho em que EG emite opinião

\begin{tabular}{|c|c|}
\hline TEXTO DE PARTIDA & TEXTO DE CHEGADA \\
\hline $\begin{array}{l}\text { All I meant was that my } \\
\text { own experience has } \\
\text { been that although at } \\
\text { least half of my own } \\
\text { books have been written, } \\
\text { albeit vaguely, for } \\
\text { children, only with The } \\
\text { Wuggly Ump did I } \\
\text { actually get one } \\
\text { published as such, } \\
\text { publishers being very } \\
\text { stupid if you ask me on } \\
\text { the whole. }\end{array}$ & $\begin{array}{l}\text { Tudo que eu quis dizer foi } \\
\text { que minha experiência foi } \\
\text { que apesar de pelo menos } \\
\text { metade dos meus próprios } \\
\text { livros terem sido escritos, } \\
\text { embora vagamente, para } \\
\text { crianças, apenas com The } \\
\text { Wuggly Ump eu de fato } \\
\text { consegui que um fosse } \\
\text { publicado dessa forma, os } \\
\text { editores foram bem burros } \\
\text { se você quer saber. }\end{array}$ \\
\hline
\end{tabular}

Fonte: GOREY (2011).

Percebemos franqueza nas palavras de EG, que confessa ter escrito grande parte de sua obra para 
o público infantil. Em 1977 essa afirmação foi posteriormente corroborada através de uma entrevista cedida a Robert Dahlin, momento em que o autor assumiu seu posicionamento publicamente e chama os editores de "sem visão": "Muitos dos meus livros foram planejados como livros infantis, e elas [editoras] não os publicaram como se fossem, o que eu sempre achei sem visão. The Wuggly Ump é o único que sempre foi publicado como livro infantil"iv (GOREY, 2001, p. 36).

Nota-se frustração em EG e uma reprovação dos editores, que são adjetivados de burros (very stupid). A escolha do adjetivo stupid poderia ser considerada inadequada em outros gêneros textuais, por tratar-se de um termo ofensivo. Por tratar-se de uma carta, esperava-se que essa confidência fosse lida apenas pelo seu destinatário, talvez por isso EG permitiu-se utilizar um palavrão. A opinião emitida na carta se assemelha àquela emitida na entrevista de Dahlin, em ambos os casos EG reprova os editores, mas enquanto na carta os chama de burros, na entrevista considera-os "sem visão", demonstrando respeito e formalidade.

Ao traduzir o excerto destacado no Quadro 2 , a intensidade do adjetivo precisa ser mantida, ainda que talvez não agrade o leitor. Dessa forma, nossa sugestão de tradução para very stupid é "bem burro", mantendo a característica ofensiva que o autor intenta transmitir. O termo "estúpido", que poderia ser uma escolha tradutória, poderia gerar uma ambiguidade inexistente no texto de partida, pois "estúpido" pode transmitir tanto a ideia de alguém sem inteligência, como alguém grosseiro, acepção que não cremos ter sido sugerida por EG. Outras possibilidades também poderiam ser pensadas, como "tolo", mas acreditamos que essa escolha perderia a intensidade da ofensa emitida no texto de partida.

No Quadro 3, EG tenta amenizar uma possível tensão decorrente de sua fala e demonstra estar convicto de que as crianças em algum momento encontram os livros que Ihes agradam:
Quadro 3 - Trecho da carta sobre literatura infantil e respectiva tradução

\begin{tabular}{|c|c|}
\hline TEXTO DE PARTIDA & TEXTO DE CHEGADA \\
\hline $\begin{array}{l}\text { In the long run I don't think } \\
\text { it matters, because } \\
\text { children eventually find } \\
\text { what is for them, as I think } \\
\text { in some slight way my } \\
\text { books have, at least with } \\
\text { children of the people who } \\
\text { have bought the books for } \\
\text { themselves, but with } \\
\text { labels being pasted on } \\
\text { everything in such } \\
\text { profusion these days until } \\
\text { you can hardly see what is } \\
\text { underneath them, if any, it } \\
\text { gives one pause. }\end{array}$ & $\begin{array}{l}\text { No final das contas eu não } \\
\text { acho que importa, porque } \\
\text { no final das contas as } \\
\text { crianças encontram o que } \\
\text { é para elas, como eu acho } \\
\text { que meio que foi com } \\
\text { meus livros, pelo menos } \\
\text { com os filhos das pessoas } \\
\text { que compraram os livros } \\
\text { para elas mesmas, mas } \\
\text { com etiquetas sendo } \\
\text { coladas em tudo de forma } \\
\text { exagerada hoje em dia de } \\
\text { forma que você mal ma } \\
\text { consegue ver o que está } \\
\text { embaixo delas, se há algo, } \\
\text { leva um tempo. }\end{array}$ \\
\hline
\end{tabular}

Fonte: GOREY (2011).

Anteriormente comentamos sobre a censura na literatura infantil, que acontece por diferentes agentes adultos, mas

É provável que as crianças-leitoras, que estão no processo de aprendizagem de normas sociais e literárias, farão uma leitura dessas normas que tenderá a construir um sentimento diferente daquele (geralmente) aceito pelos leitores adultos (ou, segundo a concepção adulta, fazem "leituras erradas" ou "más interpretações"). (HUNT, 2010, p. 34)

Para traduzir o texto de partida do Quadro 3, é importante ter conhecimento prévio sobre as dificuldades que o autor enfrentou para a publicação de suas obras e sobre questões relacionadas à literatura infantil, ou seja, conhecer o contexto em que o assunto da carta se encontra. Quanto aos desafios tradutórios de nível semântico, destacamos as expressões que indicam informalidade entre os autores: In the long run, some slight way e it gives one pause.

A informalidade é uma característica que precisa ser preservada na tradução, por isso traduzimos in the long run por "no final das contas". Essa expressão traz a ideia de algo que acontecerá em um momento futuro, outras possibilidades seriam "a longo prazo", "com o tempo", "ao longo do tempo", mas todas são mais formais que a tradução proposta. 
Em I think in some slight way my books have [...], o adjetivo slight traz a ideia de algo em pequena quantidade, "sutil". Ao traduzir essa expressão, optamos pela gíria informal "meio que", que transmite uma impressão de incompletude, sem muita certeza. Ao final do trecho destacado, o autor utiliza a expressão it gives one pause para dizer que as pessoas demoram um certo tempo para notarem o que há debaixo das catalogações feitas nos livros infantis. Optamos pela expressão "leva um tempo" para preservar a informalidade da mensagem.

Por fim, destacamos novamente, no Quadro 4, um trecho já comentado anteriormente por causa da utilização de parênteses, mas agora o enfoque está no neologismo knockdowndragout e no alimento watermelon pickle:

Quadro 4 - Trecho com indagações e desafios semânticos (coloquialismo e neologismo) e respectiva tradução

\begin{tabular}{|l|l|}
\hline TEXTO DE PARTIDA & $\begin{array}{l}\text { TEXTO DE } \\
\text { CHEGADA }\end{array}$ \\
\hline $\begin{array}{l}\text { (Incidentally, should you ever } \\
\text { wish to add a note of extreme } \\
\text { acerbity - a word I have never } \\
\text { to my knowledge used before- } \\
\text { to a conversation of ours just } \\
\text { say watermelon pickle; I think } \\
\text { we could have a real } \\
\text { knockdowndragout on the } \\
\text { acrescentar uma nota } \\
\text { de desteridade - uma } \\
\text { aubject.)) }\end{array}$ \\
$\begin{array}{l}\text { palavra que eu não } \\
\text { lembro ter usado } \\
\text { antes - a uma } \\
\text { conversa nossa } \\
\text { apenas diga } \\
\text { marmelada; eu acho } \\
\text { que nós poderíamos } \\
\text { realmente destrinchar } \\
\text { o assunto.) }\end{array}$ \\
\hline
\end{tabular}

Fonte: GOREY (2011).

$O$ fato de que os autores têm facilidade para conversar é a observação feita por EG no excerto destacado no Quadro 4. Ao utilizar o alimento watermelon pickle, EG quis demonstrar que até mesmo assuntos incomuns ou irrelevantes poderiam se transformar em grandes conversas e serem aprofundados entre eles. O remetente utiliza um termo popular e cotidiano na cultura de origem, o qual poderia ser traduzido literalmente por "conserva de melancia". Contudo, essa escolha causaria estranhamento para o leitor de chegada, que conhece diversos tipos de conservas, como as de pepino, pêssego e figo, mas não as de melancia. O ponto a ser considerado aqui é que EG não estava realmente preocupado em falar sobre conservas de melancia, mas em dizer que até mesmo esse tópico poderia suscitar conversas longas e profundas. Dessa forma, domesticar o termo de forma que o leitor compreenda que o alimento é apenas um exemplo de assunto banal seria nossa escolha nesse caso. Assim, optamos por "marmelada", um doce popularmente conhecido no Brasil e que também não costuma ser motivo de conversas longas ou profundas. A ideia de ter "um longo e intenso debate" é transmitida através do termo knockdowndragout. Sem um equivalente na língua de chegada, buscamos um termo coloquial que trouxesse a ideia de "exaurir um assunto", o que nos levou ao verbo "destrinchar".

\section{Considerações finais}

A carta, por ser considerada um gênero literário, se assemelha à tradução literária, pois contém marcas de oralidade, coloquialismo, escolhas de termos específicos e referências que demandam um olhar atento do tradutor. Por não ser um gênero que passa por revisões ou edições antes de ser enviada a seus remetentes, é comum encontrar períodos longos, redundâncias ou um uso descomedido de elementos gráficos. Sendo assim, "não podemos senão abordar a epístola como um texto movente, um mar revolto no qual os reflexos cambaleiam entre o documento biográfico e a obra literária, entre informação semântica e sentença absoluta" (ABES, 2010, p. 138).

Nos trechos traduzidos nesse artigo, notamos que a pontuação representou graficamente a oralidade contida na carta de forma que o destinatário, estando a par dos assuntos tratados, perceberia a voz do remetente ressoando nos adendos e comentários apresentados entre parênteses ou nas indagações que emitiu sem esperar respostas.

A carta é um gênero majoritariamente prosaico, e

A grande prosa - romance, carta, ensaio tem [...] uma estrutura em arborescência 
(repetições, proliferação em cascata das relativas e dos particípios, incisos, longas frases, frases sem verbo etc.) que é diametralmente oposta à lógica linear do discurso enquanto discurso (Berman, 2013, p. 68, grifo nosso).

Com isso, preservar as repetições e as marcas do discurso oral é essencial para proporcionar ao leitor do texto de chegada um efeito rítmico próximo àquele que o primeiro leitor, o destinatário da carta, teve. Da mesma forma, ao escolher como traduzir expressões coloquiais é importante pensar que efeitos tais expressões teriam para o destinatário e como o leitor da língua de chegada poderia captar isso. Se o remetente da carta usa um termo ofensivo, não acreditamos que a tradução deva suprimir essa informação, principalmente porque a carta era, até então, confidencial; diminuir uma ofensa emitida na carta seria apagar a franqueza do remetente.

Através das digressões, com fluxo da consciência, pensamentos, e compartilhamento de opiniões, essa carta nos permitiu ter acesso a um posicionamento do autor diante de suas obras e da literatura infantil. Nos deparamos com um autor que, mesmo negligenciado pelas editoras, se autodenomina escritor de literatura infantil e se satisfaz ao ter ciência de que sua obra chegou a seus leitores mesmo que acidentalmente. Percebe-se, também, uma simpatia de Gorey em relação a Neumeyer, ao trazer essa discussão à tona e esclarecer que se preocupa com a aprovação editorial da obra em desenvolvimento.

Concluímos, portanto, que a tradução do gênero epistolar exige do tradutor o reconhecimento deste gênero como um misto entre o literário e a vida real dos missivistas, repleto de marcas de oralidade, amplificado pela sensação de proximidade que as cartas dão entre seus interlocutores e que não é possível apenas estrangeirizar ou domesticar, sendo cada desafio tradutório passível de uma avaliação cuidadosa.

\section{Referências}

ABES, Gilles J. Charles Baudelaire e sua primeira Crítica de Arte- tradução de uma carta de 1838 endereçada ao coronel Aupick. Scientia Traductionis. 7.
(2010): 135-147. Portal de Periódicos da UFSC. Disponível em: $<$ https://periodicos.ufsc.br/index.php/scientia/article/view Article/13998>. Acesso em: 01 fev. 2021.

ANDRADE, Carlos Drummond. A lição do amigo: cartas de Mário de Andrade a Carlos Drummond de Andrade anotadas pelo destinatário. São Paulo: Companhia das letras, 2015.

ANDRADE, Maria Lucia da Cunha V. de Oliveira. O uso de digressões como estratégia discursiva na fala e na escrita. São Paulo: Humanitas, FFLCH/USP, FAPESP; 2002.

ANDRUETTO, María Teresa. Por uma literatura sem adjetivos. Tradução de Carmem Cacciacarro. São Paulo: Editora Pulo do Gato, 2012.

AZEVEDO, Ricardo. A didatização e a precária divisão de pessoas em faixas etárias: dois fatores no processo de (não) formação de leitores. 2003. Disponível em: $<$ http://www.ricardoazevedo.com.br/wp/wp-

content/uploads/A-didatizacao-e-a-precaria-divisao-depessoas-em-faixas-etarias.pdf> Acesso em: 10 jan. 2021.

BARRENECHEA, Ana María. La epístola y su naturaleza genérica. Dispositio. XV.39 (1990): 51-65. Department of Romance Languages, University of Michigan. Disponível em: $<$ http://www.jstor.org/stable/41491374?readnow=1\&logg edin=true\&seq=1\#page scan tab contents $>$. Acesso em: 25 mar. 2021.

BERMAN, Antoine. A Tradução e a Letra ou o Albergue do Longínquo. Tradução de Marie-Hélène C. $2^{\mathrm{a}}$ ed. Tubarão: Copiart. Florianópolis: PGET/UFSC, 2013.

BOHRER, Andréa L. B. Tradução comentada de uma seleção de cartas de Edward Lear: outro olhar sobre $O$ autor do livro de Nonsense. (2015). Dissertação de Mestrado em Estudos da Tradução. Universidade Federal de Santa Catarina. 2015. Repositório Institucional da UFSC. Disponível em: $<$ https://repositorio.ufsc.br/xmlui/bitstream/handle/123456 $789 / 160702 / 338070$.pdf? sequence $=1$ \&isAllowed $=\mathrm{y}>$. Acesso em: 10 nov. 2020.

BOSSIS, M.; MCPHERSON, K. Methodological Journeys Through Correspondences. Yale French Studies, n. 71, p. 63-75, 1986.

BOVO, Cláudia Regina. No âmago da epistolografia medieval: tipologia epistolar e política na correspondência de Pedro Damiano (1040-1072). História (São Paulo) v.34, n.2, p. 263-285, jul./dez. 2015. ISSN 1980-4369. Doi: http://dx.doi.org/10.1590/1980436920150002000068

BUONAFINA, Maria Tereza. As Ultime lettere di Jacopo Ortis, de Ugo Foscolo: tradução comentada e anotada de seleção da obra. (2006). Dissertação de Mestrado em Letras. Universidade de São Paulo. Dissertação de Metrado em Letras. Disponível em: $<$ http://www.teses.usp.br/teses/disponiveis/8/8148/tde13082007-151702/pt-br.php > Acesso em: 13 fev. 2021.

FRANCISCO, Reginaldo. Estrangeirização e domesticação: indo além de mais uma dicotomia. Scientia Traductionis, n.16, 2014. Disponível em: 
https://periodicos.ufsc.br/index.php/scientia/article/view/1 9804237.2014n16p91/31977. Acesso em: 29 abr. 2021.

GALINDO, Caetano Waldrigues. A Rosa is a rose is a rose: avaliando traduções de Grande sertão: veredas para o inglês. O Eixo e a Roda: Revista de Literatura Brasileira, [S.I.], v. 25, n. 1, p. 87-108, ago., 2016. ISSN 2358-9787. Disponível em: $<$ http://www.periodicos.letras.ufmg.br/index.php/o eixo e a roda/article/view/10234>. Acesso em: 29 mai. 2021. doi:http://dx.doi.org/10.17851/2358-9787.25.1.87-108.

GOREY, Edward. Conversations with Writers: Edward Gorey. In: Wilkin, Karen (Ed.) Ascending Peculliarity: Edward Gorey on Edward Gorey. Entrevista concedida a Robert Dahlin (1977). Orlando: Library of Congress, 2001, p. 24-49.

GOREY, Edward. [Carta] "4.xi.68” 04 Nov. 1968. Floating Worlds: The Letters of Edward Gorey \& Peter F. Neumeyer. Ed. Peter F. Neumeyer. Petaluma: Pomegranate Communications, Inc., 2011: 89-90.

HUNT, Peter. Crítica, teoria e literatura infantil. Tradução de Cid Knipel. São Paulo: Cosac Naify, 2010. Impresso.

MARTÍN BAÑOS, Pedro. El arte epistolar en el Renacimiento europeo: 1400-1600. Bilbao: Publicaciones de la Universidad de Deusto, 2005.

MEIRELES, Cecília. Problemas da literatura infantil. $3^{\text {a }}$ ed. Rio de Janeiro: Nova Fronteira, 1984.

NEUMEYER, Peter F. "Introdução". In: Floating Worlds: The Letters of Edward Gorey \& Peter F. Neumeyer. Petaluma: Pomegranate Communications, Inc., 2011.

NEUMEYER, Peter F. Interview by Susan Resnik. San Diego State University Oral Histories. Abr. 2010. $11 / 02 / 2020$ Disponível

em

i Todas as citações de línguas estrangeiras foram traduzidas pelos autores.

ii [...] la epístola tiene la ventaja de ser un producto universal que se manifiesta en todas las culturas que poseen sistemas de escritura

iii It's a message written by one individual to another individual who is far away. This writing - a substitute for direct speech, which distance has
$<$ https://library.sdsu.edu/scua/sdsu-oralhistories/neumeyer> Acesso em jan. 2021.

RÓNAI, Paulo. A tradução vivida. $4^{\mathrm{a}}$ ed. Rio de Janeiro: José Olympio, 2012.

SCHLEIERMACHER, Friedrich D. E. Sobre os diferentes métodos de tradução. In: Heidermann, Werner (Org.) Clássicos da Teoria da Tradução. Tradução de Celso R. Braida. 2ª ed. Florianópolis: UFSC, 2010, p. 38-99.

TESCH, L. M. O uso de digressões em textos orais". Filologia E Linguística Portuguesa, vol. 17, nำ 2, abril de 2016, p. 273-9, doi: 10.11606/issn.2176-9419.v17i2p273293.

VASCONCELLOS, Eliane. Carta-missiva. Remate de Males, Campinas, SP, v. 18, p. 62-70, 2012. Disponível em:

https://periodicos.sbu.unicamp.br/ojs/index.php/remate/ar ticle/view/8636136. Acesso em: 28 abr. 2021

VENUTI, Lawrence. The translator's invisibility: a history of translation. London/New York: Routledge, 1995.

\section{COMO CITAR ESSE ARTIGO}

MICOANSKI THOMAZINE, Angelica; DA SILVA OLIVEIRA, Cláudio Luiz. DESAFIOS TRADUTÓRIOS EM UMA PROPOSTA DE TRADUÇÃO EPISTOLAR. Signo, Santa Cruz do Sul, v. 46, n. 87, sep. 2021. ISSN 1982-2014. Disponível em: $<$ https://online.unisc.br/seer/index.php/signo/article/vi ew/16537>.

doi:https://doi.org/10.17058/signo.v46i87.16537..

made impossible - has a utilitarian value, directly linked to daily life [...]

iv A lot of my books were intended as children's books, and they would not publish them as such, which I always thought was very shortsighted. The Wuggly Ump is the only one that's ever been published as a children's book. 